\title{
Tropical wetlands, climate, and land-use change: adaptation and mitigation opportunities
}

\author{
R. K. Kolka • D. Murdiyarso · J. B. Kauffman • \\ R. A. Birdsey
}

Received: 11 March 2016/Accepted: 12 March 2016/Published online: 2 April 2016

(C) Springer 2016

\section{Introduction}

Tropical wetland ecosystems, especially mangroves and peatlands, are carbon $(\mathrm{C})$ rich ecosystems. Globally, tropical mangroves store about $20 \mathrm{PgC}$, however, deforestation has contributed $10 \%$ of the total global emissions from tropical deforestation, even though mangroves account for only about $0.7 \%$ of the world's tropical forest area (Donato et al. 2011). Meanwhile, tropical peatlands store $191 \mathrm{PgC}$ or approximately $33 \%$ of global peatland C (Post et al. 1982; Page and Rieley 1999). This disproportionate capacity of tropical wetlands to sequester and store $\mathrm{C}$ make them a critical component in understanding

R. K. Kolka ( $ه)$

U.S.D.A Forest Service Northern Research Station,

Grand Rapids, MN, USA

e-mail: rkolka@fs.fed.us

D. Murdiyarso · J. B. Kauffman

Center for International Forestry Research, Bogor 16115, Indonesia

D. Murdiyarso

Department of Geophysics and Meteorology, Bogor

Agricultural University, Bogor 16680, Indonesia

J. B. Kauffman

Oregon State University, Corvallis, OR, USA

R. A. Birdsey

U.S.D.A Forest Service Northern Research Station,

Newtown Square, PA, USA local, regional and global $\mathrm{C}$ stocks that influence the balance of greenhouse gases to and from the atmosphere.

Tropical wetlands provide many valuable ecosystem services in addition to $\mathrm{C}$ storage and accumulation. They are some of the most biodiverse wetlands in the world for both floral and faunal species (Junk et al. 2006). Mangrove systems are important rearing areas for fish and shellfish and responsible for $48 \%$ to near $100 \%$ of their production where mangroves exist (Rönnbäck 1999). Mangrove systems are also especially important for abatement of impacts from hurricanes and tsunamis as they provide a barrier to wind and waves (Alongi 2008).

Unfortunately, there are increasing conversion pressures on these valuable ecosystems for the production of food, fiber, and other products. As a result, tropical peatlands are being burned, ditched, and converted to other land uses such as oil palm production at an alarming rate (Murdiyarso et al. 2010; Koh et al. 2011). Similarly, mangrove ecosystems are being converted to other uses such as shrimp ponds at rates never seen previously (Murdiyarso et al. 2013; Spalding et al. 2010). The staggering rates of conversion of these valuable ecosystems compels us to develop a better understanding of the current functions they provide so that we can better understand climate change adaptation and mitigation opportunities.

Because of the importance of tropical wetlands, we developed a cooperation among the USDA Forest Service's International Programs, the U.S. State 
Department and USAID, the Center for International Forestry Research and Oregon State University to address research needs, strategize on developing adaptation and mitigation opportunities, and build capacity in countries where these valuable ecosystems are present. The Sustainable Wetlands Adaptation and Mitigation Program (SWAMP) has been leading many wetland research studies across the tropics, sponsored numerous trainings to develop local and regional capacity, and worked with countries policy and natural resource officials to develop adaptation and mitigation strategies.

The combination of SWAMP and its predecessor, the Tropical Wetlands Initiative for Climate Adaptation and Mitigation (TWINCAM) have been pursuing issues related to tropical wetlands since 2009. As a result, the SWAMP principal investigators thought it was an appropriate time and place to have a special session at the 2014 International Union of Forest Research Organizations (IUFRO) 24th World Congress held in Salt Lake City, UT, USA. We convened a special technical session under the Forests and Climate Change Theme entitled "Tropical Forest Wetlands, Climate, and Land-use Change: Adaptation and Mitigation Opportunities," with the objective of presenting and discussing recent research on carbon stocks and greenhouse gas emissions from intact and converted wetland forests and associated land uses, ecosystem $\mathrm{C}$ dynamics modeling tools, and roles of tropical wetlands in climate change adaptation and mitigation strategies. We opened the call to all researchers working on tropical wetlands. We had a vibrant, well-attended session with 9 oral presentations and 2 posters. Following the special session, we put out a call for papers for a special journal issue of Wetlands Ecology and Management dedicated to tropical wetlands.

This special issue on tropical wetlands has 11 papers that went through the normal journal review process and are presented starting with a paper by Hribljan et al. (2016) focusing on high elevation peatlands in Ecuador, followed by a paper that compares $\mathrm{C}$ stocks in tropical peatlands and mangroves in Mexico (Adame and Fry 2016), and then a series of 9 papers assessing mangrove dynamics from Africa (Stringer et al. 2016; Tang et al. 2016; Trettin et al. 2016), South and Latin America (Bhomia et al. 2016; Kauffman et al. 2016; McFadden et al. 2016), and Southeast Asia (Nam et al. 2016; MacKenzie et al.
2016). The final paper is a global review on impacts of rising ocean water levels on mangrove ecosystems (Sasmito et al. 2016).

\section{Summary of findings}

Results reported by Hribljan et al. (2016) indicated that little-studied high altitude Andean peatlands in the páramo ecozone of Ecuador contained thick horizons of $\mathrm{C}$ dense soils interbedded with mineral material derived predominately from volcanic deposition. Peatland soil depths averaged $3.8 \mathrm{~m}$ and contained $1282 \mathrm{Mg} \mathrm{C} \mathrm{ha}{ }^{-1}$. Carbon dating indicated that older peatlands $(>3000$ cal. Year. BP) had a much slower rate of $\mathrm{C}$ accumulation $\left(26 \mathrm{~g} \mathrm{~m}^{-2}\right.$ year $^{-1}$ ) than those $<500$ cal. year. BP $\left(134 \mathrm{~g} \mathrm{~m}^{-2}\right.$ year $\left.^{-1}\right)$. The large magnitude of $\mathrm{C}$ stored in páramo peatlands and their high sequestration rate, especially for younger peatlands, led the authors to conclude that Ecuadorean mountain peatlands are critically important for local to regional $\mathrm{C}$ storage and additional studies are needed to provide fundamental baseline characterization for $\mathrm{C}$ inventories in the Andes.

Adame and Fry (2016) assessed C and nitrogen (N) across a gradient of Mexican riverine wetlands that included forested peatland, marsh and mangrove ecosystems. Utilizing $\mathrm{C}$ and $\mathrm{N}$ isotopes they were able to ascertain that sources and processes related to $\mathrm{C}$ storage differed across the gradient. In the forested peatland and marsh, soils have experienced higher decomposition and changes in plant communities that led to differences in $\mathrm{C}$ sources, possibly a result of frequent fires and nutrient enrichment from upstream agricultural activities. In mangroves, the $\mathrm{C}$ accumulation was driven by burial of in situ production with little change in burial rates over the past century. The authors concluded that mangrove forests are a better geomorphological setting than forested peatlands and marshes for long-term storage of $\mathrm{C}$ and $\mathrm{N}$.

Stringer et al. (2016) assessed the spatial variability of mangrove soil physical and chemical properties within the Zambezi River Delta in Mozambique and determined whether it may be associated with geomorphic setting (seaward fringe, creek, riverine, and interior). While many statistically significant differences were shown with depth and geomorphic setting, the variability of the measured characteristics was low when compared to other mangrove settings. Carbon 
concentrations ranged from 1.38 to $2.38 \% \mathrm{C}$ and bulk density ranged from 0.75 to $1.02 \mathrm{~g} \mathrm{~cm}^{-3}$. Unlike the results reported by Adame and Fry (2016), stable isotopic signatures showed that the organic matter is likely a mix of mangrove and marine sources, with mangrove-derived sources contributing 42-58 \%.

Tang et al. (2016) used geospatial techniques to estimate mangrove extent, mangrove biomass and $\mathrm{C}$ stored in biomass in nine West African countries. They used NASA derived products to estimate mangrove canopy height and spatially explicit analysis based on allometric equations to convert to both above- and belowground biomass and associated C. Overall the total mangrove biomass and $\mathrm{C}$ for West Africa were estimated as $273 \mathrm{Tg}$ and $136 \mathrm{Tg}$, respectively. Among individual countries, Nigeria has the most mangrove biomass and carbon but Cameroon has the highest mean mangrove biomass and $\mathrm{C}$ density. The scientists suggested that their approach can be used to estimate the distribution, biomass, and $\mathrm{C}$ stored in biomass in other regions and at other spatial scales.

Trettin et al. (2016) used a stratified random sampling design based on mangrove tree height derived from remote sensing to estimate biomass pools in the Zambezi River Delta, Mozambique. They used a spatial decision support system to allocate field sample plots across five categories of tree heights. The 8 species of mangrove were found to be in heterogeneous mixtures across all 5 height classes. Basal area ranged from 14 to $41 \mathrm{~m}^{2} \mathrm{ha}^{-1}$ and the diameter distribution indicated allaged stands. Aboveground biomass ranged from 111 to $483 \mathrm{Mg} \mathrm{ha}^{-1}$ with $92 \%$ of the biomass found in the overstory live trees. They recommended that similar approaches using a stratified random approach and remote sensing should be considered in future inventories of mangrove ecosystems.

Bhomia et al. (2016) quantified C stocks in mangrove ecosystems on the Bay Islands and both the Caribbean and Pacific coasts of Honduras. They describe the $\mathrm{C}$ stocks of mangrove forests regionally, and separated among three commonly used height classes. Mangrove ecosystem $\mathrm{C}$ stocks ranged from $570 \mathrm{Mg} \mathrm{C}^{-1}$ in the Pacific Coast to about $1000 \mathrm{Mg}$ $\mathrm{C} \mathrm{ha}^{-1}$ in the Caribbean Coast and Bay Islands. Across height classes, low mangroves ( $<3 \mathrm{~m}$ height) had a mean of $1200 \mathrm{Mg} \mathrm{Cha}^{-1}$, followed by tall mangroves ( $>10 \mathrm{~m}$ in height) with a mean of $900 \mathrm{Mg} \mathrm{Cha}^{-1}$ and medium mangroves (3-10 $\mathrm{m}$ in height) with a mean of $800 \mathrm{Mg} \mathrm{C} \mathrm{ha}{ }^{-1}$. Of the ecosystem C pools sampled, soils overwhelming were the largest comprising $>80 \%$ of the total ecosystem C stock at all locations. They found a significant correlation between vegetation $\mathrm{C}$ pools and pore water salinity and $\mathrm{pH}$. The authors concluded by emphasizing that $\mathrm{C}$ sequestration is just one of the ecosystem services that mangrove ecosystems provide and that they should be considered during the formulation of climate change mitigation strategies in Central America.

In the Pantanos de Centla of Mexico, Kauffman et al. (2016) compared C stocks between intact mangrove systems and cattle pastures formed from mangroves. The mean ecosystem $\mathrm{C}$ stock of intact mangroves was $1358 \mathrm{Mg} \mathrm{C}$ ha $^{-1}$ while that of converted cattle pastures was $458 \mathrm{Mg} \mathrm{C} \mathrm{ha}^{-1}$. Conversion affected soil properties to depths of at least $2 \mathrm{~m}$. Based on the equivalence of mass of the top $1 \mathrm{~m}$ of soil, the cattle pastures have lost at least $1464 \mathrm{Mg}$ $\mathrm{CO}_{2}$ equivalents $\mathrm{ha}^{-1}$. Those losses are considerably greater than land cover change in upland tropical forest types. Also, carbon stock declines through greenhouse gas fluxes is just one of many ecosystem services impacted by land use conversion of mangroves. As a result, conservation of these important ecosystems should be a priority.

McFadden et al. (2016) conducted a study assessing the nutrient enrichment of water bird nesting sites in mangrove ecosystems of Honduras. Nutrient deposition, and nutrients in soil and vegetation were compared between a site within a nesting colony and an adjacent site without a nesting colony. The nesting colony rookery had a mean of 1721 nests $\mathrm{ha}^{-1}$ and deposited an estimated $1.12 \mathrm{Mg} \mathrm{N}^{-1}$ and $0.16 \mathrm{Mg}$ $\mathrm{P} \mathrm{ha}^{-1}$ in guano over a 120 day breeding season. The added deposition led to $8 \mathrm{X}$ more plant available nitrate, $2 \mathrm{X}$ more plant available ammonium and $7 \mathrm{X}$ more plant available phosphorus in soils under the nesting colony compared to soils without a nesting colony. Similarly, mangrove leaves had higher concentrations of $\mathrm{N}$ and $\mathrm{P}$ in the nesting colony site. The authors consider that further research is needed to understand the avian effects on mangrove growth rates, nutrient export from rookery sites and on other associated faunal communities.

Nam et al. (2016) compared vegetation metrics and ecosystem C stocks between two types of restored mangrove forest (planted vs. natural regeneration) in the Mekong Delta Region of Vietnam. Among the two restoration approaches, no differences were found in 
vegetation structure or ecosystem-level C stocks, although mangrove species diversity was higher in forests restored through planting. Overall, their results indicated that after 35 years, both planted and naturally regenerated mangrove forests store similar levels of $\mathrm{C}$ and are not dramatically different in vegetation factors. Considering the lack of differences, restoring through natural regeneration would likely be the most cost effective restoration approach.

MacKenzie et al. (2016) measured sedimentation, vertical accretion, and belowground $\mathrm{C}$ accumulation rates of mangrove ecosystems in the Republic of Palau and Vietnam in an effort to assess vulnerability of these ecosystems to sea level rise. They compared how plant diversity, land use (disturbed sites in Palau were influenced by a highway and naturally colonized versus replanted mangroves in Vietnam) and location of mangroves (fringe vs. interior) influence sedimentation, vertical accretion and belowground $\mathrm{C}$ accumulation rates. Vertical accretion rates were greater in Vietnam than Palau and positively correlated with plant diversity and bulk density, both of which were higher in Vietnam. Vertical accretion rates were similar between naturally colonized and planted sites in Vietnam, and between natural and highway influenced sites in Palau. Carbon accumulation rates ranged from 69 to $602 \mathrm{~g} \mathrm{C} \mathrm{m}^{-2}$ year $^{-1}$ and did not differ between plant diversity class, land use or location. Based on vertical accretion rates, both Vietnamese and Palauan mangroves are keeping up with current rates of sea level rise.

Sasmito et al. (2016) did a systematic review of the literature to find available data on both mangrove surface elevation change and surface accretion rates to conduct a global meta-analysis to compare to the latest IPCC predictions of sea level rise. They found that mangrove hydrogeomorphic setting was an important criteria for vulnerability to sea level rise, with basin mangroves ecosystems less susceptible than fringe mangrove ecosystems. Fringe mangrove ecosystems associated with small islands appear to be especially vulnerable to sea level rise. Mangrove degradation (e.g. urban development or harvesting) had a negative effect on surface elevation change while rehabilitation had a positive effect indicating that degraded systems are most susceptible to sea level rise. Although this study was able to begin to discern the vulnerability of mangrove ecosystems globally, the authors strongly recommend a global expansion of surface elevation monitoring is needed to better assess the factors affecting mangrove resiliency in the face of rising sea levels.

\section{Conclusion}

Combined, this special issue of Wetlands Ecology and Management highlights the importance of tropical wetlands on the global $\mathrm{C}$ balance, and other ecosystem services such as livelihood options, biodiversity conservation and resiliency of coastal ecosystems to sea level rise. Further, degradation of tropical wetlands results in dramatic shifts in ecosystem function from long-term $\mathrm{C}$ sinks to significant sources of greenhouse gases. Understanding the impacts of degradation and land use change on these C-rich ecosystems will be critical to predict future impacts of global climate. Restoring or rehabilitating tropical wetlands can reverse $\mathrm{C}$ losses and can be valuable components to climate change adaptation and mitigation strategies. Although this special issue adds new data on these vulnerable ecosystems, it also demonstrates the need for future research on these important ecosystems.

We believe that critical future research falls into three broad areas. First, although we are making great strides at mapping current tropical wetland ecosystem C stocks, we still have a lot of area to investigate. Mapping tropical wetland ecosystem $\mathrm{C}$ stocks needs to consider both the aerial coverage of wetlands and their $\mathrm{C}$ density. Remote sensing and ground truthing such as that used in the Tang et al. (2016) paper appears to be the approach that will allow us to most efficiently map aerial extent. Similar studies need to be conducted globally for both mangrove and peatland aerial coverage in the tropics. Measuring $\mathrm{C}$ density requires an intense field campaign where vegetation, soils and sometimes other $\mathrm{C}$ pools are measured (e.g. dead wood). Those campaigns are expensive but necessary to develop a baseline understanding of $\mathrm{C}$ density. If $\mathrm{C}$ density has relationships to remote sensing parameters such as mangrove height as in the Trettin et al. (2016) and the Bhomia et al. (2016) papers, C stocks can be scaled to larger landscapes. Although protocols for measuring $\mathrm{C}$ density have been produced (Kauffman and Danato 2012), rapid assessment techniques (Chimner et al. 2014) should be considered that balance both an acceptable level of uncertainty with the effort and expense to acquire the data. A recent announcement from the Indonesian government is 
awarding \$1 million US dollars to develop a rapid protocol for mapping the extent and thickness of Indonesian peatlands.

Second, we need a better understanding on the effect of management and land use change on C stocks of tropical wetlands. Although we have a considerable challenge to be able to map C stocks in unmanaged wetlands, challenges are even greater to gain a better understanding on how management and land use change are affecting $\mathrm{C}$ stocks and greenhouse gas fluxes to the atmosphere. These values are critical to calculate emission factors for countries to account for their $\mathrm{C}$ footprint. Unfortunately there are so many possible scenarios of management and land use change it is extremely difficult to broadly characterize $\mathrm{C}$ gains and losses from these changes. We need more site specific studies such as Kauffman et al. (2016) where we have side by side comparisons of $\mathrm{C}$ stocks in managed and unmanaged ecosystems. Moreover, we also have little information regarding tropical wetland restoration or enhancement where degraded systems could be used for mitigation opportunities.

Third, the value of non-C related ecosystem services that tropical wetlands provide is understudied. Although it is commonly understood the tropical wetlands provide a variety of critical services, more data on the magnitude and significance of other services is needed to justify their conservation and restoration. Similar to $\mathrm{C}$ related ecosystem services, very little is known how management and land use change affect non-C related services. Although in the study by McFadden et al. (2016) comparisons were not between mangroves under different management, the use of one system as a rookery showed significant changes to the soil pool of nutrients. Similar studies need to be conducted between unmanaged tropical wetlands and managed and changed systems to understand impacts on biodiversity, nutrient cycling, rearing of fish and shellfish and abatement potential for wind and waves along coastlines.

Funding None.

\section{References}

Adame F, Fry B (2016) Source and stability of soil carbon in mangrove and freshwater wetlands of the Mexican Pacific coast. Wetlands Ecol Manag. doi:10.1007/s11273-0159475-6

Alongi DM (2008) Mangrove forests: resilience, protection from tsunamis, and responses to global climate change. Estuar Coast Shelf Sci 76:1-13

Bhomia RK, Kauffman JB, McFadden TN (2016) Ecosystem carbon stocks of mangrove forest along the Pacific and Caribbean coasts of Honduras. Wetlands Ecol Manag. doi:10.1007/s11273-016-9483-1

Chimner RA, Ott CA, Perry CH, Kolka RK (2014) Developing and evaluating rapid field methods to estimate peat carbon. Wetlands 34:1241-1246

Donato DC, Kauffman JB, Murdiyarso D, Kurnianto S, Stidham M, Kanninen M (2011) Mangroves among the most carbon-rich forests in the tropics. Nat Geosci 4:293-297

Hribljan JH, Suarez E, Heckman K, Lilleskov E, Chimner R (2016) Peatland carbon stocks and accumulation rates in the Ecuadorian Páramo. Wetlands Ecol Manag. doi:10. 1007/s11273-016-9482-2

Junk WJ, Brown M, Campbell IC, Finlayson M, Gopal B, Ramberg L, Warner BG (2006) The comparative biodiversity of seven globally important wetlands: a synthesis. Aquat Sci 68:400-414

Kauffman JB, Danato D (2012) Protocols for the measurement, monitoring and reporting of structure, biomass and carbon stocks in mangrove forests. CIFOR Working Paper no. 46. Center for International Forestry Research (CIFOR), Bogor, Indonesia

Kauffman JB, Trejo HH, Garcia MDCJ, Heider C, Contreras W (2016) Carbon stocks of mangroves and losses arising from their conversion to cattle pastures in the Pantanos de Centla, Mexico. Wetlands Ecol Manag. doi:10.1007/ s11273-015-9453-z

Koh LP, Miettinen J, Liew SC, Ghazoul J (2011) Remotely sensed evidence of tropical peatland conversion to oil palm. Proc Natl Acad Sci 108:5127-5132

Mackenzie R, Foulk PB, Klump JV, Purbospito J, Murdiyarso D, Donato D, Nam VM (2016) Sedimentation and belowground carbon accumulation rates in mangrove forests that differ in diversity and land use: a tale of two mangroves. Wetlands Ecol Manag. doi:10.1007/s11273016-9481-3

McFadden TN, Kauffman JB, Bhomia RK (2016) Effects of nesting waterbirds on nutrient levels in mangroves, Gulf of Fonseca, Honduras. Wetlands Ecol Manag. doi:10.1007/ s11273-016-9480-4

Murdiyarso D, Hergoualc'h K, Verchot LV (2010) Opportunities for reducing greenhouse gas emissions in tropical peatlands. Proc Natl Acad Sci 107:19655-19660

Murdiyarso DB, Kauffman JB, Verchot LV (2013) Climate change mitigation strategies should include tropical wetlands. Carbon Manag 4:509-517

Nam VN, Sasmito SD, Murdiyarso D, Purbopuspito J, Mackenzie RA (2016) Carbon stocks in artificially and naturally regenerated mangrove ecosystems in the Mekong Delta. Wetlands Ecol Manag. doi:10.1007/s11273-0159479-2

Page SE, Rieley JO (1999) Tropical peatlands: a review of their natural resource functions, with particular reference to Southeast Asia. Int Peat J 8:95-106 
Post WM, Emanuel WR, Zinke PJ, Stangenberger AG (1982) Soil carbon pools and world life zones. Nature 298:156-159

Rönnbäck P (1999) The ecological basis for economic value of seafood production supported by mangrove ecosystems. Ecol Econ 29:235-252

Sasmito SD, Murdiyarso D, Friess DA, Kurnianto S (2016) Can mangroves keep pace with contemporary seal level rise?: A global data review. Wetlands Ecol Manag. doi:10.1007/ s11273-015-9466-7

Spalding MD, Kainuma M, Collins L (2010) World Atlas of Mangroves. Earthscan, London
Stringer CE, Trettin CC, Zarnoch SJ (2016) Soil properties of Mangroves in contrasting geomorphic setting within the Zambezi River Delta, Mozambique. Wetlands Ecol Manag. doi:10.1007/s11273-015-9478-3

Tang W, Feng W, Jia M, Shi J, Zou H, Trettin CC (2016) The assessment of mangrove biomass and carbon in West Africa: a spatially explicit analytical framework. Wetlands Ecol Manag. doi:10.1007/s11273-015-9474-7

Trettin CC, Stringer CE, Zarnoch S (2016) Composition, biomass and structure of mangroves within the Zambezi River Delta. Wetlands Ecol Manag. doi:10.1007/s11273-0159465-8 